\title{
ERRATUM
}

\section{School environment and policies, child eating behavior and overweight/obesity in urban China: the childhood obesity study in China megacities}

P Jia, M Li, H Xue, L Lu, F Xu and Y Wang

International Journal of Obesity (2017) 41, 1310; doi:10.1038/ijo.2017.125

Correction to: International Journal of Obesity (2017) 41, 813-819; doi:10.1038/ijo.2017.2

The following paragraph on page 814:

Weight status: Overweight was defined based on the International Obesity Task Force-recommended age- and sex-specific cutoffs corresponding to $\mathrm{BMI}=25 \mathrm{~kg} \mathrm{~m}^{-2}$ at age 18 years. ${ }^{26}$ Obesity was defined based on the International Obesity Task Forcerecommended age- and sex-specific cutoffs corresponding to $\mathrm{BMI}=3025 \mathrm{~kg} \mathrm{~m}^{-2}$ at age 18 years.
Should read:

Weight status: Overweight was defined based on the International Obesity Task Force-recommended age- and sex-specific cutoffs corresponding to $\mathrm{BMI}=25 \mathrm{~kg} \mathrm{~m}^{-2}$ at age 18 years. ${ }^{26}$ Obesity was defined based on the International Obesity Task Forcerecommended age- and sex-specific cutoffs corresponding to $\mathrm{BMI}=30 \mathrm{~kg} \mathrm{~m}^{-2}$ at age 18 years.

The typesetter would like to apologize for their error. 